\title{
In situ pulse respirometric methods for the estimation of kinetic and stoichiometric parameters in aerobic microbial communities
}

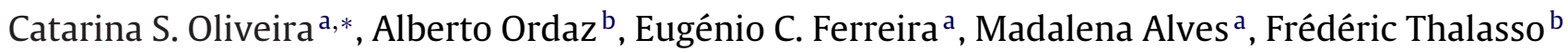 \\ a IBB-Institute for Biotechnology and Bioengineering, Centre of Biological Engineering, University of Minho, Campus de Gualtar, 4710-057 Braga, Portugal \\ ${ }^{\mathrm{b}}$ Centro de Investigación y Estudios Avanzados del IPN (Cinvestav), Depto. Biotecnología, Av. IPN. 2508, San Pedro Zacatenco, C.P. 07360, Mexico DF, Mexico
}

\section{A R T I C L E I N F O}

\section{Article history:}

Received 12 April 2011

Received in revised form 26 June 2011

Accepted 6 August 2011

Available online 16 August 2011

\section{Keywords:}

Aerobic processes

Kinetic parameters

Heterotrophes

ASM

Pirt

In situ respirometry

Chemostat

\begin{abstract}
A B S T R A C T
In situ pulse respirometry was applied in an activated sludge bubble column treating synthetic wastewater for the estimation of the (i) maximum specific oxygen consumption rate, (ii) substrate affinity constant (iii) biomass growth yield, (iv) maintenance coefficient, and (v) specific endogenous respiration rate. Parameters obtained from respirometry were compared to those obtained by the chemostat method, based on substrate and biomass measurements, under several dilution rates. The low sensitivity of substrate measurement methods and the difficulties of sampling heterogeneous biomass suspension are critical issues limiting the applicability of the chemostat method. Additionally, the extensive time consuming nature of this method allows concluding that chemostat method presents several disadvantages in comparison with in situ pulse respirometric techniques. Parameters were obtained from respirograms by fitting ASM1 and ASM3 models, and from experiments performed by injecting pulses of increasing substrate concentration. The injection of pulses of increasing concentration was the most adequate method, with several advantages such as a simpler experimental data interpretation, and results with better confidence.

Considering the assessment and comparison of the experimental and calculation methods presented, it is recommended that the estimation of kinetic and stoichiometric parameters in mixed aerobic cultures should preferentially be performed by using in situ respirometric techniques.
\end{abstract}

(c) 2011 Elsevier B.V. All rights reserved.

\section{Introduction}

Respirometry is the measurement of the biological oxygen consumption rate under well defined conditions [1]. The interest of respirometry for parameter estimation, compared to techniques based on substrate concentration measurement, is that dissolved oxygen (DO) concentration can be measured easily and continuously with relative small input of experimental effort and obtaining high-quality data [2]. DO concentration changes in the order of ten parts-per-billion can be monitored online at high frequency.

Notwithstanding the potential advantages of respirometric methods, kinetic and stoichiometric parameters are still largely determined by substrate mass balances in batch or chemostat culture. From these, chemostat is still widely accepted as a suitable method for determining the substrate affinity constant $\left(K_{\mathrm{S}}\right)$ [3-5]. It consists in measuring the residual limiting substrate concentration for different dilution rates. The growth limiting substrate is directly measured at concentrations close to $K_{\mathrm{S}}$ [6], being

\footnotetext{
* Corresponding author. Tel.: +351 253604 400; fax: +351 253604429.

E-mail addresses: catarinaoliveira@deb.uminho.pt, cat_ss_oli@msn.com (C.S. Oliveira)
}

precision and accuracy of substrate measurements pointed as the main limitation of the method [7]. Additionally, reaching steady state takes considerable time, thus the method is especially time consuming as it requires the operation of the reactor under several steady states. Drawbacks of traditional methods may be overcome by respirometry $[8,9]$.

Within many respirometric techniques, pulse respirometry, developed in the late 80 s and mid 90 s is probably one of the most used [10-13]. It consists in measuring DO concentration after the injection into the system of a defined substrate concentration pulse. The exogenous oxygen uptake rate $\left(\mathrm{OUR}_{\mathrm{ex}}\right)$ curves reflect the kinetic of the aerobic biodegradation process and allow the estimation of kinetic and stoichiometric parameters. After the injection of substrate pulses, the kinetic parameters are usually estimated by direct model fitting to a respirometric curve $[8,11,14]$. Alternatively, Cech et al. [10] proposed a method in which kinetic parameters are obtained from the observed respirometric response of the endogenous system to the injection of substrate pulses of increasing concentration.

The determination of the oxidation yield $\left(\mathrm{Y}_{\mathrm{O}_{2} / \mathrm{S}}\right)$ and the growth yield $\left(Y_{\mathrm{X} / \mathrm{S}}\right)$ by pulse respirometry is also commonly done by model fitting to a respirometric curve [2]. However, parameter identifiability analysis showed that $Y_{\mathrm{X} / \mathrm{S}}$ cannot be estimated accurately and 


\section{Nomenclature}

ASM1, 3 activated sludge model 1, 3

ATU allylthiourea

$b_{\mathrm{H}} \quad$ specific endogenous respiration rate $\left(\mathrm{h}^{-1}\right)$

$b_{\text {Sto }} \quad$ specific respiration rate for $X_{\text {Sto }}\left(\right.$ ASM3) $\left(\mathrm{h}^{-1}\right)$

c maintenance constant of Neijssel and Tempest model [32] (-)

C DO concentration $\left(\mathrm{mg} \mathrm{O}_{2} \mathrm{~L}^{-1}\right)$

$C_{\mathrm{b}} \quad$ baseline DO concentration $\left(\mathrm{mg} \mathrm{O}_{2} \mathrm{~L}^{-1}\right)$

$\mathrm{C}^{*} \quad$ saturation DO concentration $\left(\mathrm{mg} \mathrm{O}_{2} \mathrm{~L}^{-1}\right)$

COD chemical oxygen demand

COD-S soluble COD fraction

COD-X insoluble COD fraction

$D \quad$ dilution rate $\left(\mathrm{d}^{-1}\right)$

DO dissolved oxygen $\left(\mathrm{mg} \mathrm{O}_{2} \mathrm{~L}^{-1}\right)$

$D_{(\mathrm{K}-\mathrm{S})} \quad$ Kolmogorov-Smirnov goodness of fit statistic

$F_{(i, j)} \quad F$ ratio (ANOVA)

HRT hydraulic retention time (d)

$k \quad$ maintenance constant of Pirt (1982) model [33] (-)

$k_{\mathrm{L}} a \quad$ oxygen volumetric mass transfer coefficient $\left(\mathrm{h}^{-1}\right)$

$K_{\mathrm{S}} \quad$ substrate affinity constant $\left(\mathrm{mg} \mathrm{COD}-\mathrm{S} \mathrm{L}^{-1}\right)$

$k_{\text {Sto }} \quad$ storage rate constant (ASM3) (gCOD-SgCOD$\mathrm{X}^{-1} \mathrm{~h}^{-1}$ )

$K_{\text {Sto }} \quad$ saturation constant for $X_{\text {Sto }}$ (ASM3) (mg COD$\mathrm{X}_{\text {Sto }} \mathrm{L}^{-1}$ )

$m \quad$ maintenance coefficient of Pirt (1965) [31] (g COD$\mathrm{Sg}$ COD $-\mathrm{X}^{-1} \mathrm{~h}^{-1}$ )

$m^{\prime} \quad$ maintenance coefficient of Neijssel and Tempest [32] (g COD-S g COD-X ${ }^{-1} \mathrm{~h}^{-1}$ )

$m^{\prime \prime} \quad$ maintenance coefficient of Pirt (1982) [33] (g COD$\mathrm{Sg}$ COD $-\mathrm{X}^{-1} \mathrm{~h}^{-1}$ )

OUR $_{\text {ex }}$ exogenous oxygen uptake rate $\left(\mathrm{mg} \mathrm{O}_{2} \mathrm{~L}^{-1} \mathrm{~h}^{-1}\right)$

OUR $_{\text {ex }}$ max maximum exogenous oxygen uptake rate $\left(\mathrm{mg} \mathrm{O}_{2} \mathrm{~L}^{-1} \mathrm{~h}^{-1}\right)$

$p \quad$ probability ( $p$-value)

$q_{\mathrm{O}_{2} \text { max }}$ maximum specific oxygen consumption rate $\left(\mathrm{g} \mathrm{O}_{2} \mathrm{~g} \mathrm{COD}^{\left.-\mathrm{X}^{-1} \mathrm{~h}^{-1}\right)}\right.$

RMSE root mean squared error (-)

$r^{2} \quad$ square correlation coefficient (-)

$S \quad$ substrate concentration ( $\left.\mathrm{mg} \mathrm{COD}-\mathrm{S} \mathrm{L}^{-1}\right)$

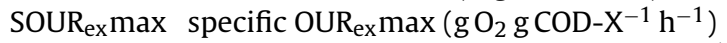

$S_{\mathrm{P}} \quad$ pulse substrate concentration ( $\left.\mathrm{mg} \mathrm{COD}-\mathrm{S} \mathrm{L}^{-1}\right)$

SRT sludge retention time (d)

$t$ time (h)

$t_{\mathrm{r}} \quad$ response time of the process $(\mathrm{h})$

$t_{\text {mix }} \quad$ mixing time of the reactor $(\mathrm{s})$

$X \quad$ biomass concentration ( $\left.\mathrm{mgCOD}-\mathrm{XL}^{-1}\right)$

$X_{\text {Sto }} \quad$ internal storage material (ASM3) $\left(\mathrm{mg} \mathrm{COD} \mathrm{X}_{\mathrm{Sto}} \mathrm{L}^{-1}\right)$

$Y_{\mathrm{O}_{2} / \mathrm{S}} \quad$ substrate oxidation yield $\left(\mathrm{g} \mathrm{O}_{2} \mathrm{gCOD} \mathrm{S}^{-1}\right)$

$Y_{\text {Sto }} \quad$ storage yield (ASM3) ( $\mathrm{g} \mathrm{COD} \mathrm{X}_{\mathrm{Sto}} \mathrm{g} \mathrm{COD} \mathrm{S}^{-1}$ )

$Y_{\mathrm{X} / \mathrm{S}} \quad$ biomass growth yield (g COD-Xg COD-S ${ }^{-1}$ )

$Y_{\mathrm{X} / \mathrm{S}}^{\prime} \quad$ true $Y_{\mathrm{X} / \mathrm{S}}\left(\mathrm{g}\right.$ COD-Xg COD-S $\left.{ }^{-1}\right)$

$Y_{\mathrm{X} / \mathrm{Sto}}$ biomass growth yield on $X_{\mathrm{Sto}}$ (ASM3) (gCOD${\mathrm{XgCOD}-\mathrm{X}_{\text {Sto }}}^{-1}$ )

$\mu \quad$ specific growth rate $\left(\mathrm{d}^{-1}\right)$

simultaneously with kinetic parameters by model fitting [15]. An alternative strategy for $Y_{\mathrm{X} / \mathrm{S}}$ determination is to consider the total exogenous oxygen consumed during the pulse injection [16].

Pulse respirometry is also of interest to determine inhibition constants $[17,18]$, oxygen affinity constants [19], wastewater biodegradability $[20,21]$, and to estimate maintenance coefficients
Table 1

List of parameters estimated and method used.

\begin{tabular}{lll}
\hline Parameter & COD balance/chemostat & Pulse respirometry \\
\hline$Y_{\mathrm{X} / \mathrm{S}}$ & $\sqrt{ }$ & $\sqrt{ }$ \\
$Y_{\mathrm{O}_{2} / \mathrm{S}}$ & & $\sqrt{ }$ \\
$q_{\mathrm{O}_{2} \max }$ & $\sqrt{ }$ & $\sqrt{ }$ \\
$K_{\mathrm{S}}$ & $\sqrt{ }$ & $\sqrt{ }$ \\
$m$ & $\sqrt{ }$ & $\sqrt{ }$ \\
$b_{\mathrm{H}}$ & & $\sqrt{ }$ \\
\hline
\end{tabular}

$(m)$ and endogenous respiration rates $\left(b_{\mathrm{H}}\right)$, which are both important for a proper description of microbial kinetics [22,23].

So far, literature on respirometry has given a special emphasis to parameters retrievability, identifiability, precision, and sensitivity, but, it has comparatively been given less focus to the accuracy of the retrieved parameters through the comparison between parameters obtained by respirometry and other methods [24]. The aim of the present research paper is to find a suitable method for the estimation of kinetic and stoichiometric parameters in mixed cultures, using suspended activated sludge as model system. With this purpose two categories of estimation methods are assessed: (i) chemostat method, and (ii) in situ pulse respirometry. Additionally, two respirometric methods are compared: respirograms model fitting in the context of ASM1 and ASM3; and a method based on the injection of pulses of increasing substrate concentration.

\section{Materials and methods}

\subsection{Experimental strategy}

A lab-scale reactor was operated during 270 days under several dilution rates $(D)$. This allowed the estimation of the main stoichiometric and kinetic parameters, namely $Y_{\mathrm{X} / \mathrm{S}}$ (biomass growth yield), $Y_{\mathrm{O}_{2} / \mathrm{S}}$ (substrate oxidation yield), $q_{\mathrm{O}_{2}}$ max (maximum specific oxygen consumption rate), $K_{\mathrm{S}}$, and maintenance coefficient $(m)$ by respirometry and by traditional chemostat method. Additionally, the endogenous respiration rate $\left(b_{H}\right)$ was only estimated by respirometry (Table 1 ).

\subsection{Experimental setup}

A transparent acrylic reactor was used $(0.14 \mathrm{~m}$ internal diameter, $0.56 \mathrm{~m}$ height, $8.6 \mathrm{~L}$ working volume). Air was continuously supplied through a porous plate $(0.09 \mathrm{~m}$ diameter $)$ located at the bottom of the reactor, with a constant air flow rate of $0.60 \mathrm{~L} \mathrm{~min}^{-1}$. The air flow rate was controlled by a mass flow-controller (Aalborg, Model GFC 17, Denmark). The reactor was continuously fed with synthetic wastewater, containing $\left(\mathrm{mg} \mathrm{L}^{-1}\right)$ : gelatine peptone, 640; meat extract, 440; urea, $120 ; \mathrm{NaCl}, 28 ; \mathrm{CaCl}_{2} \cdot 2 \mathrm{H}_{2} \mathrm{O}$, 16; $\mathrm{MgSO}_{4} \cdot 6 \mathrm{H}_{2} \mathrm{O}, 8 ; \mathrm{K}_{2} \mathrm{HPO}_{4}, 34 ; \mathrm{Na}_{2} \mathrm{HPO}_{4}, 134 ; \mathrm{NH}_{4} \mathrm{Cl}, 6.8$; total chemical oxygen demand (COD), $1198 \pm 11$; soluble COD, $1087 \pm 17 ; \mathrm{C} / \mathrm{N}$ ratio, 2.6 (g/g). Allylthiourea (ATU) was added to the synthetic wastewater solution $\left(10 \mathrm{mg} \mathrm{ATU}^{-1}\right)$ in order to inhibit nitrification. The synthetic wastewater was fed continuously with peristaltic pumps (Watson Marlow $101 \mathrm{U} / \mathrm{R}, 405 \mathrm{U} / \mathrm{R} 1$ or $401 \mathrm{U} / \mathrm{D} 1$, depending on the flow rate). Effluent was collected by overflow in a refrigerated tank $\left(4^{\circ} \mathrm{C}\right)$ for posterior analysis. $\mathrm{pH}$ was maintained at $7.0 \pm 0.5$, by addition of $0.5 \mathrm{M} \mathrm{NaOH}$ or $0.2 \mathrm{M} \mathrm{H}_{2} \mathrm{SO}_{4}$ (Control System/Pump BL7917, Hanna Instruments, USA). The reactor was inoculated with $1 \mathrm{~L}$ of mixed liquor obtained from a conventional wastewater treatment plant (Cambados-Maia, Portugal). The reactor was maintained at ambient room temperature $\left(19-23^{\circ} \mathrm{C}\right)$.

The reactor was characterised in terms of mixing time $\left(t_{\text {mix }}\right)$ by lithium chloride pulse experiments [9]. $t_{\mathrm{mix}}$ was defined as the time required for the lithium concentration in the reactor, after the injection of a pulse, to reach $90 \%$ of the final lithium concentration. The 
$t_{\text {mix }}$ was determined as follows: (i) the reactor feeding was stopped, (ii) a known concentration of lithium chloride was injected at the bottom of the reactor, (iii) samples were taken from the top of the reactor, and (iv) after stable lithium concentration was observed, the reactor feeding was switched back on. The lithium concentration was measured by atomic absorption (Varian SPECTRAA 250 Plus, USA).

\subsection{Reactor operation}

After inoculation, the reactor was operated under fed-batch mode for 5 days. During this period, about 20\% of the mixed liquor was substituted every day. After this adaptation period, the reactor was operated continuously during 270 days under five $D$ (from 0.2 to $2.0 \mathrm{~d}^{-1}$ ) and, consequently, five organic loading rates (from 0.2 to $2.3 \mathrm{~g} \mathrm{COD}-\mathrm{S} \mathrm{L}^{-1} \mathrm{~d}^{-1}$ ). Each $D$ tested was maintained at least until steady-state was reached, the steady state is defined as constant degradation rate and biomass concentration (variations within normal standard deviations).

\subsection{Methods}

\subsubsection{Analytical procedures}

Influent and effluent were characterised through triplicate measurements of the total and soluble COD. COD was determined using the closed reflux colorimetric method, according to standard methods [25]. Substrate concentration $(S)$ was considered to be the soluble COD fraction (COD-S), and biomass concentration $(X)$ the insoluble COD fraction (COD-X), estimated as the difference between total COD and soluble COD. Soluble and insoluble COD fractions were separated by filtration $(0.45 \mu \mathrm{m})$.

\subsubsection{Pulse respirometry and data interpretation}

The DO concentration was measured online with a polarographic oxygen probe, located at the top of the reactor and connected to a DO-meter (Hannah Instrument HI2400, USA) and a computer for data acquisition. DO readings were corrected for temperature, salinity, and altitude through DO-meter automatic compensation adjustments. The oxygen probe was calibrated before each respirometric experiment. Saturation DO concentration $\left(C^{*}\right)$ was experimentally measured under the experimental conditions of the reactor, using sterilised effluent coming out from the reactor. Oxygen mass transfer coefficient $\left(k_{\mathrm{L}} a\right)$ was determined from the dynamic method, as it was described by Badino et al. [26]. The response time of the electrode was taken into account during respirometric and $k_{\mathrm{L}} a$ measurements.

In situ respirometric pulse experiments were done according to the following procedure: (i) the reactor was maintained until stable DO readings were obtained; (ii) the substrate feeding was stopped and the aeration maintained; (iii) the DO concentration slowly increased until reaching a new pseudo-stationary state, called baseline oxygen concentration $\left(C_{\mathrm{b}}\right)$ corresponding to endogenous respiration [27]; (iv) a pulse of synthetic wastewater, containing ATU (reactor concentration of $10 \mathrm{mg} \mathrm{ATU} \mathrm{L}^{-1}$ ), was injected in order to obtain a substrate concentration in the reactor $\left(S_{\mathrm{P}}\right)$ of approximately $20 \mathrm{mg} \mathrm{COD}-\mathrm{S} \mathrm{L}^{-1}$; (v) the DO concentration was acquired until the system returned to $C_{\mathrm{b}}$; (vi) additional pulses were eventually injected (10-40 $\mathrm{mg} \mathrm{COD}-\mathrm{S} \mathrm{L}^{-1}$ ); and (vii) the $k_{\mathrm{L}} a$ was measured in triplicate before the feeding of the reactor was restored. The initial substrate to biomass ratio $\left(S_{0} / X_{0}\right)$ applied with the pulses was between 0.03 and $0.2 \mathrm{~g}$ COD-S g COD- $\mathrm{X}^{-1}$.

The respirometric data interpretation method was as previously reported [28-30]. Briefly, after the injection of a known substrate pulse concentration $\left(S_{\mathrm{P}}\right)$, the $Y_{\mathrm{O}_{2} / \mathrm{S}}$ was given by the amount of oxygen consumed per unit $\mathrm{COD}$ of substrate oxidised
(Eq. (1)). $Y_{\mathrm{X} / \mathrm{S}}$ expressed in COD units was estimated from $Y_{\mathrm{O}_{2} / \mathrm{S}}$ (Eq. (2)).

$Y_{\mathrm{O}_{2} / \mathrm{S}}=\frac{\int_{0}^{t} \mathrm{OUR}_{\mathrm{ex}} \mathrm{d} t}{S_{\mathrm{P}}}=\frac{k_{\mathrm{L}} a \int_{0}^{t}\left(C_{\mathrm{b}}-C\right) \mathrm{d} t}{S_{\mathrm{P}}}$

$Y_{\mathrm{X} / \mathrm{S}}=1-Y_{\mathrm{O}_{2} / \mathrm{S}}=1-\frac{k_{\mathrm{L}} a \int_{0}^{t}\left(C_{\mathrm{b}}-C\right) \mathrm{d} t}{S_{\mathrm{P}}}$

The average $Y_{\mathrm{X} / \mathrm{S}}$ estimated at each $D$ by respirometry were used to estimate the maintenance coefficient $(m)$ according to the Pirt method [31] (Eq. (3)). Models including a variable maintenance were also considered such as the Neijssel and Tempest model [32] (Eq. (4)), and the 1982 Pirt model [33] (Eq. (5)). In these models, since the system was considered at steady state and completely mixed, the specific growth rate $(\mu)$ was considered equal to $D$.

$$
\begin{aligned}
& \frac{1}{Y_{\mathrm{X} / \mathrm{S}}}=\frac{1}{Y^{\prime} \mathrm{X} / \mathrm{S}}+m \frac{1}{\mu} \\
& \frac{1}{Y_{\mathrm{X} / \mathrm{S}}}=\frac{1}{Y^{\prime} \mathrm{X} / \mathrm{S}}+m^{\prime} \frac{1}{\mu}+c m^{\prime} \\
& \frac{1}{Y_{\mathrm{X} / \mathrm{S}}}=\frac{1}{Y_{\mathrm{X} / \mathrm{S}}^{\prime}}+m \frac{1}{\mu}+m^{\prime \prime}\left(\frac{1-k \mu}{\mu}\right)
\end{aligned}
$$

During pulse respirometry, $C_{\mathrm{b}}$ was typically inferior to $C^{*}$. This difference was accounted for endogenous respiration [27,34]. In this work, $m$ estimated from Eqs. (3)-(5), was compared to the specific endogenous respiration rate $\left(b_{\mathrm{H}}\right)$ estimated from Eq. (6).

$b_{\mathrm{H}}=\frac{k_{\mathrm{L}} a\left(C^{*}-C_{\mathrm{b}}\right)}{X}$

$q_{\mathrm{O}_{2} \text { max }}$ and $K_{\mathrm{S}}$ were estimated by model fitting to respirometric data, as it was previously described [28]. Briefly, after the injection of a substrate pulse, the DO concentration in the reactor was described by a balance between the exogenous respiratory activity and the oxygen provided by continuous aeration [35], being $C$ the DO concentration in the liquid phase. Additionally, the response time of the process $\left(t_{r}\right)$ was taken into account in a similar manner as described previously by Vanrolleghem et al. [36].

$\frac{\mathrm{d} C}{\mathrm{~d} t}=\left[k_{\mathrm{L}} a\left(C_{\mathrm{b}}-C\right)-\mathrm{OUR}_{\mathrm{ex}}\right]\left(1-e^{-t / t_{\mathrm{r}}}\right)$

In Eq. (7), two models were used to describe OUR $\mathrm{ex}_{\mathrm{x}}$ and fitted to experimental DO data: the ASM1 model [37], and the ASM3 model [38]. Table 2 shows the matrix representation of the models used. The main difference between both models is that ASM3 model considers substrate storage.

Eq. (7) was adjusted to the experimental data obtained from the pulse experiments with a fitting procedure based on Runge-Kutta method and a Marquardt optimisation method with 20 convergence steps (Model Maker, Cherwell Scientific Publishing, UK). $q_{\mathrm{O}_{2} \text { max }}$ was obtained by dividing the estimated OUR $\mathrm{ex}_{\mathrm{ex}}$ max by the biomass concentration in the reactor $(X)$.

Additionally to model fitting, $q_{\mathrm{O}_{2} \text { max }}$ and $K_{\mathrm{S}}$ were also estimated after the injection of pulses of increasing substrate concentration, as it was reported by Orupold et al. [39]. The observed SOUR $\mathrm{ex}_{\mathrm{max}}$ (specific OUR $\mathrm{R}_{\mathrm{ex}}$ max, obtained by dividing OUR $\mathrm{ex}_{\mathrm{ex}} \max$ by $X$ ) was plotted against the substrate concentration pulse. The graph obtained showed a clear Monod-type shape (Eq. (8)), used to estimate $q_{\mathrm{O}_{2} \max }$ and $K_{\mathrm{S}}$.

$\mathrm{SOUR}_{\mathrm{ex}} \max =q_{\mathrm{O}_{2} \max }\left(\frac{S_{\mathrm{P}}}{K_{\mathrm{S}}+S_{\mathrm{P}}}\right)$

\subsubsection{Chemostat method}

$Y_{\mathrm{X} / \mathrm{S}}$ was estimated from the biomass produced (difference between total and soluble COD of the effluent) and the substrate 
Table 2

Simplified matrix of ASM1-like and ASM3 models for organic carbon removal, considering soluble biodegradable COD.

\begin{tabular}{|c|c|c|c|c|c|}
\hline Component process & $S$ & $X_{\text {Sto }}$ & $X$ & C & Rate \\
\hline Substrate consumption (ASM1) & $-\frac{1}{Y_{\mathrm{O}_{2} / \mathrm{S}}}$ & & & -1 & $\operatorname{OUR}_{\mathrm{ex}} \max \frac{S}{K_{\mathrm{S}}+S}$ \\
\hline Storage of $S$ (ASM3) & -1 & $Y_{\text {Sto }}$ & & $-\left(1-Y_{\text {Sto }}\right)$ & $k_{\mathrm{Sto}} X \frac{S}{K_{\mathrm{S}}+S}$ \\
\hline Growth on $X_{\text {Sto }}($ ASM3) & & $-\frac{1}{Y_{\mathrm{X} / \text { Sto }}}$ & 1 & $-\frac{\left(1-Y_{\mathrm{X} / \mathrm{Sto}}\right)}{Y_{\mathrm{X} / \mathrm{Sto}}}$ & $\mu_{\max } X \frac{\left(X_{\text {Sto }} / X\right)}{K_{\text {Sto }}+\left(X_{\text {Sto }} / X\right)}$ \\
\hline Respiration of $X_{\text {sto }}$ (ASM3) & & -1 & & -1 & $b_{\text {Sto }} X_{\text {Sto }}$ \\
\hline
\end{tabular}

consumed (difference between influent and effluent soluble COD). The average of $Y_{\mathrm{X} / \mathrm{S}}$ estimated at each $D$, were used to determine the maintenance coefficient $(m)$ according to the Pirt method [31] (Eq. (3)), as it was done with data obtained by respirometry. $q_{\mathrm{O}_{2} \max }$ and $K_{\mathrm{S}}$ were estimated by fitting the Monod equation to the average experimental data (SOUR $\mathrm{ex}_{\mathrm{e}}$ and $S$ ) determined at each dilution rate, under steady-state. With that purpose, SOUR $_{\text {ex }}$ was estimated from the total COD removed.

\subsubsection{Statistical analysis of the results}

Models goodness of fit was estimated through the comparison of three parameters: (i) the correlation factor $\left(r^{2}\right)$, (ii) the root mean squared error (RMSE), and (iii) the Kolmogorov-Smirnov test [40]. Significance of difference between parameters was estimated through One-way ANOVA and Tukey's HSD post hoc test, using PASW Statistics 18 (SPSS Inc. Package).

Average values are presented with the corresponding standard error.

\section{Results and discussion}

\subsection{Reactor operation}

The reactor was inoculated with activated sludge from a local wastewater plant, and operated under fed-batch mode. After 5 days, a clear biomass growth was observed (approximately from 400 to $500 \mathrm{mg}$ COD-X L ${ }^{-1}$ ), corroborated by an increase in substrate degradation activity. Time was reset and the reactor was then operated under continuous mode for 270 days. The reactor worked with a constant influent concentration of $1.06 \pm 0.09 \mathrm{~g} \mathrm{COD}^{-S \mathrm{~S} \mathrm{~L}^{-1}}$. Five dilution rates were tested, from 0.19 to $1.95 \mathrm{~d}^{-1}$. The first tested $D\left(0.45 \mathrm{~d}^{-1}\right)$ was maintained for 170 days. The additional $D$ (i.e., $0.19,0.28,0.91$, and $1.95 \mathrm{~d}^{-1}$ ) were maintained for a time corresponding to six hydraulic retention times (HRT) at least. Fig. 1 shows the reactor's behaviour during the continuous operation. The system adapted adequately to the variations of the organic loading rate, imposed by the variations of $D$, presenting a stable COD removal efficiency during the whole operation $(90-100 \%$ soluble

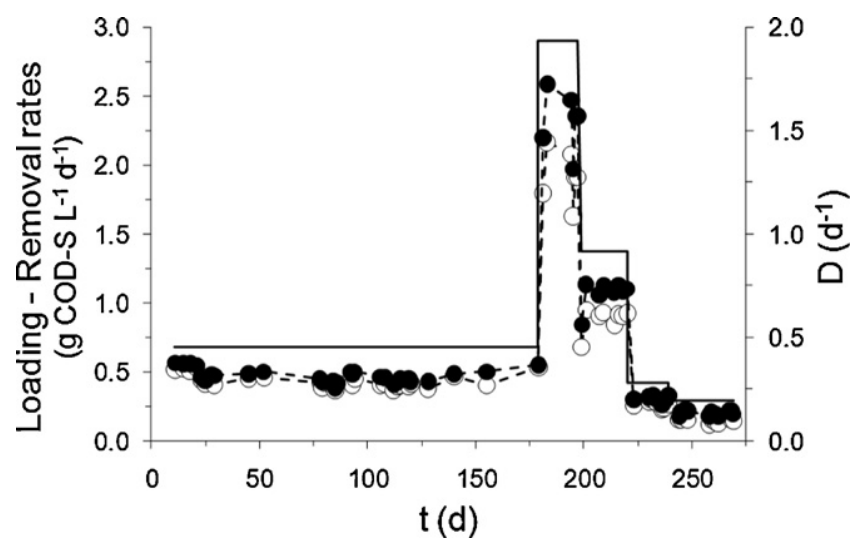

Fig. 1. Behaviour of the reactor: dilution rate $(D,-)$, loading rate $(\bullet)$, and removal rate $(\bigcirc)$.
Table 3

Sludge retention time (SRT) and biomass concentration $(X)$ achieved at each of the tested dilution rates $(D)$

\begin{tabular}{lll}
\hline$D\left(\mathrm{~d}^{-1}\right)$ & SRT $(\mathrm{d})$ & $X\left(\mathrm{mgCOD}-\mathrm{XL}^{-1}\right)$ \\
\hline 2.0 & 0.5 & $674.6 \pm 203.0$ \\
0.9 & 1.1 & $595.4 \pm 156.4$ \\
0.5 & 2.2 & $454.4 \pm 191.2$ \\
0.3 & 3.6 & $377.7 \pm 148.4$ \\
0.2 & 5.2 & $193.2 \pm 57.2$ \\
\hline
\end{tabular}

COD removal). Table 3 presents information on sludge retention time (SRT) and biomass concentration $(X)$ achieved at each tested $D$. A quasi-linear $\left(r^{2}=0.98\right)$ decrease of $X$ was observed with the SRT increase. This can be explained by the increase of substrate limitations to biomass growth as dilution rate decreased, and SRT increased.

The mixing time of the reactor $\left(t_{\text {mix }}\right)$ was determined in two periods: at the beginning of operation, on day 10 , when a $t_{\text {mix }}$ of $19 \pm 2$ s was obtained; and at the end of operation, on day 250 , when a $t_{\text {mix }}$ of $22 \pm 2 \mathrm{~s}$ was obtained. These low $t_{\text {mix }}$ values, comparatively to HRT, show that the bubble-column reactor was a well-mixed system.

The first pulse experiments were done on day 20. Fig. 2 shows a superposition of two respirograms obtained after feeding suppression and injection of two successive pulses of $22 \mathrm{mg} \mathrm{COD}-\mathrm{S} \mathrm{L}^{-1}$. Fig. 2 shows that DO concentration decreased sharply immediately after pulse injection (time 0 ) and then, after $2 \mathrm{~h}$, returned to the baseline value $\left(C_{\mathrm{b}}\right)$ of $8.2 \mathrm{mg} \mathrm{L}^{-1}$. Both respirograms showed a similar shape with a square correlation coefficient $\left(r^{2}\right)$ between them of 0.99 . At the end of the second pulse, after $6 \mathrm{~h}$ of respirometric experiments, the substrate feeding was turned back on, and the system returned to normal operation. No changes were observed in DO, biomass, nor substrate concentrations compared to the situation observed before the respirometric experiments (results not shown). These results confirm that in situ pulses are reproducible and that feeding suspension during approximately $6 \mathrm{~h}$ did not affect significantly the behaviour of the system.

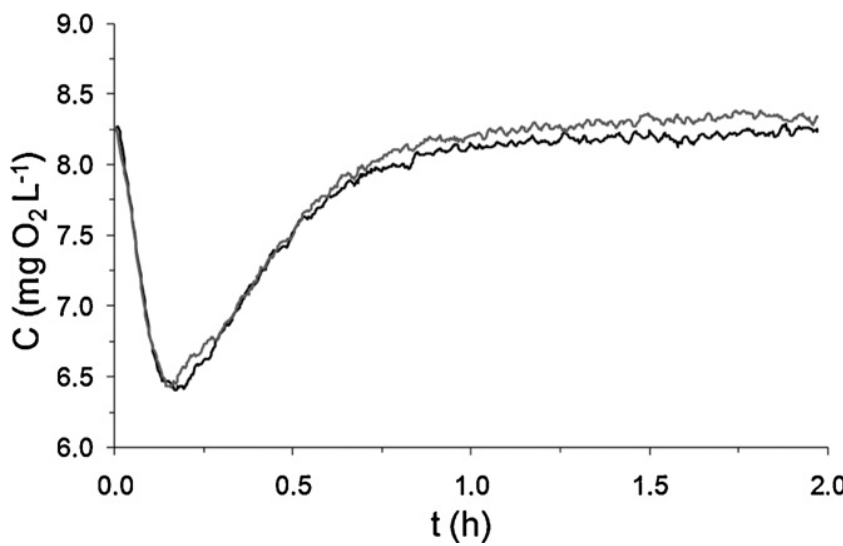

Fig. 2. Superposition of two respirograms observed after the injection of two consecutive pulses of $22 \mathrm{mg} \mathrm{COD}^{-S_{\mathrm{L}}^{-1}}$ : first pulse (darker line), and second pulse (lighter line). 


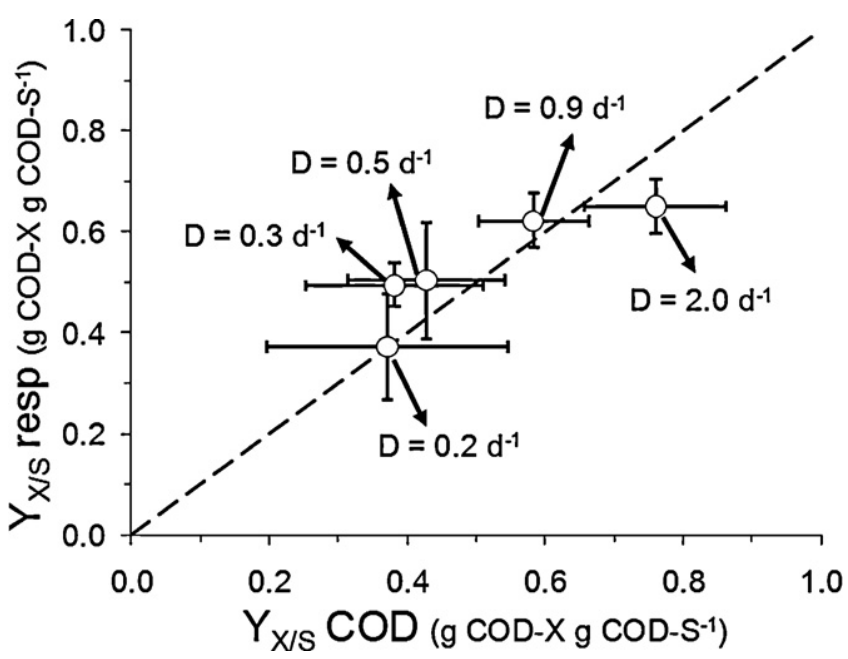

Fig. 3. Correlation between the biomass growth yields $\left(Y_{\mathrm{X} / \mathrm{S}}\right)$ estimated by respirometry and by COD mass balance. The dotted line represents the linear regression forced to cross the origin.

\section{2. $Y_{X / S}$ and $m$}

$Y_{\mathrm{X} / \mathrm{S}}$ was estimated by respirometry (Eq. (2)) from the area of the 51 respirograms obtained during the whole reactor operation, and also by COD mass balance. Fig. 3 presents a comparison of the average $Y_{X / S}$ values for each dilution rate. The slope of the linear regression forced to cross the origin was 1.01 , with a $r^{2}$ of 0.98 , meaning that the values obtained with both methods were comparable. Very recently, Di Trapani et al. [41] found, in a membrane bioreactor, a significant difference between the $Y_{\mathrm{X} / \mathrm{S}}$ values obtained by pulse respirometry and by COD mass balance. This discrepancy of values was suggested to be related with two terms, (i) the fact that respirometric pulses were done with a readily biodegradable substrate for characterisation of biomass acclimated to real wastewater, and (ii) the influence of biomass decay phenomenon, which is taken into account by the COD mass balance method, but not by the respirometric method due to the short time of experiments Biomass decay was probably an important factor in Di Trapani et al. [41] work, as they used a membrane bioreactors with high sludge retention. In the present work no discrepancy was observed between $Y_{\mathrm{X} / \mathrm{S}}$ values obtained by pulse respirometry and by COD mass balance, probably because the same complex substrate was used to feed the reactor and for respirometric pulses, and because the reactor used was completely mixed with no biomass retention in excess to hydraulic retention, thus where decay phenomenon was negligible. Regardless of the proximity of the $Y_{\mathrm{X} / \mathrm{S}}$ values obtained by pulse respirometry and by COD mass balance, the average standard deviation of the respirometric method (15\%) was lower than the average standard deviation of the COD balance method (27\%). The higher standard deviation of the COD method is likely due to the required biomass sampling procedures, which are not necessary with in situ respirometric methods. This constitutes one advantage of respirometry.

From the $Y_{X / S}$ determined by respirometry, and by COD mass balance, $m$ was determined graphically (Fig. 4) according to the Pirt's method [31] (Eq. (3)). Maintenance coefficients, $m$, estimated by the COD mass balance and by respirometry, were, respectively, $0.012 \pm 0.012$ and $0.010 \pm 0.006 \mathrm{~h}^{-1}$. Considering that the results were obtained over 270 days with a mixed culture that was certainly changing in composition over time [42], it is not surprising that with neither one of the methods a perfect linear correlation was obtained. Nevertheless, the $r^{2}$ of the respirometric method was significantly higher (0.90) than the correlation of the COD method

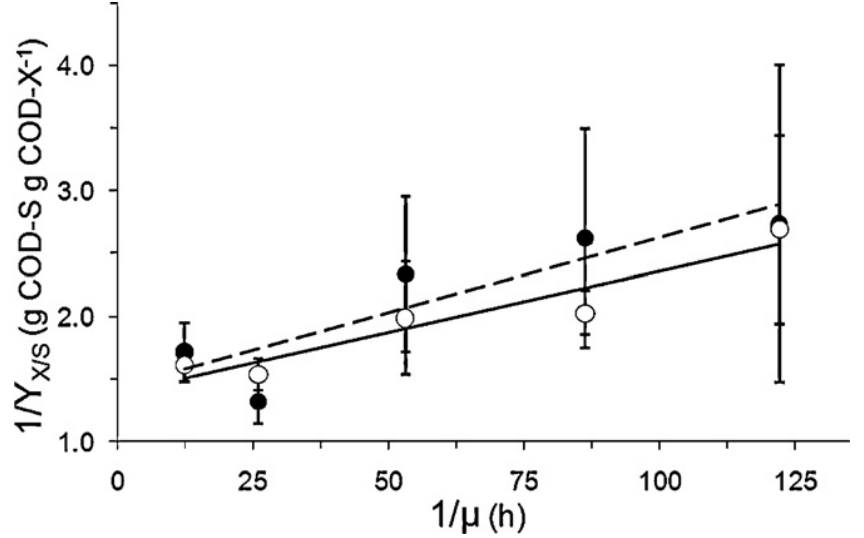

Fig. 4. Pirt [27] linearisation of the experimental growth yield estimated from COD mass balance $(\bullet$, dotted line $)$, and by respirometry $(\bigcirc$, solid line).

(0.78), confirming that methods based on biomass sampling are affected by intrinsic errors due to the difficulty of sampling heterogeneous suspensions. The 1982 Pirt [33], and the Neijssel and Tempest [32] models were unsuccessfully applied $\left(r^{2}<0.70\right)$ to the same experimental data (results not shown).

As mentioned before, the difference between $C_{b}$ and the $C^{*}$ during respirometric experiments is typically accounted for endogenous respiration $[27,34]$. In order to compare maintenance $(m)$ and endogenous respiration $\left(b_{\mathrm{H}}\right)$, the baseline DO concentration was measured before each of the 51 pulses made along the reactor operation. From these data, the estimation of $b_{\mathrm{H}}$ from Eq. (6) was $0.025 \pm 0.015 \mathrm{~h}^{-1}$. This result shows that $b_{\mathrm{H}}$ was superior to $m\left(0.010 \pm 0.006 \mathrm{~h}^{-1}\right)$ estimated with respirometric data from Pirt's model [31]. The difference between $b_{\mathrm{H}}$ and $m$ deserves a close attention. The difference between $m$ and $b_{\mathrm{H}}$ can be explained by the fact that different non-growth processes are considered in each case $[22,43]$. The endogenous respiration includes osmoregulation, cell mobility, defence mechanisms, proofreading, and internal turnover of macromolecular compounds. According to these authors, $m$ neglects some of these processes and is therefore expected to be lower than $b_{\mathrm{H}}$, as it was observed in this work.

\section{3. $K_{S}$ and $q_{O_{2} \max }$}

ASM1 and ASM3 models were adjusted to the respirograms obtained along the reactor operation. Fig. 5 shows an example of data fitting using both models. Table 4 shows average values of the correlation factor, the RMSE and the Kolmogorov-Smirnov goodness of fit $\left(D_{(\mathrm{K}-\mathrm{S})}\right)$ after the analysis of 51 pulses made

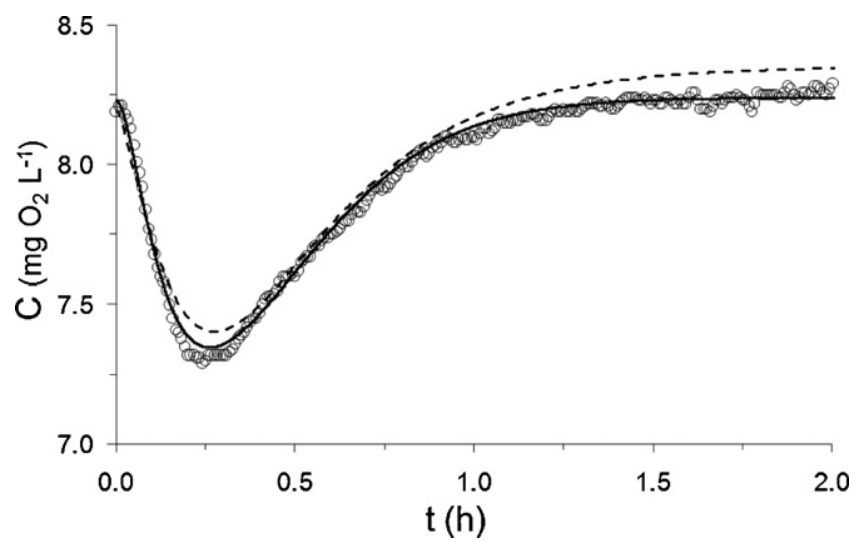

Fig. 5. Example of a respirogram ( $\bullet)$, model fitting using ASM1 $\left(r^{2}=0.99\right.$, solid line $)$ and ASM3 $\left(r^{2}=0.95\right.$, dotted line $)$. 
Table 4

Average values of the correlation factor, the RMSE and the $D_{(\mathrm{K}-\mathrm{S})}$ value for ASM1 and ASM3 fitting to respirograms.

\begin{tabular}{lll}
\hline & ASM1 & ASM3 \\
\hline$r^{2}$ & 0.97 & 0.91 \\
RMSE & 0.07 & 0.13 \\
$D_{(\mathrm{K}-S)}$ & 0.19 & 0.39 \\
\hline
\end{tabular}

during the reactor operation. The correlation factor of ASM1 model was superior to that of ASM3. Both RMSE and $D_{(\mathrm{K}-S)}$ were lower for the ASM1 than for the ASM3 model. These results confirm that ASM1 model adjusted better the experimental data, which is an indication that storage was not significant in this process. This is in accordance with literature, as storage mechanism is generally observed in sludge subjected to dynamic conditions. Krishna and van Loosdrecht [44] stated, for instance, that, under continuous feeding, activated sludge systems have a low storage capacity. More recently, Ciggin et al. [45] indicated that biomass acclimated to continuous feeding could not store the excess substrate even when a sudden change in the feeding was done. In the present work, the reactor was maintained under steady-state, and the biomass never experienced dynamic conditions of substrate concentration, except when substrate pulses were done. However, a maximum of 2 pulses per day were done and each sequence of pulses was parted by 15 to $70 \mathrm{~h}$. According to Vanrolleghem et al. [46] it is expected that the biomass had no time to adapt its enzymatic system to storage. Prendl and Kroiss [47] did not observe storage when the sludge age was below 5 days. In the present work, except in the last $D$ tested $\left(0.2 \mathrm{~d}^{-1}\right)$, the sludge age was below 5 days. At last, it has been reported that storage occurs when sludge is subjected to nutrient or oxygen limitation with excess of substrate. In this work, the pulses were made of complete medium, including nutrients, and DO was always above $2 \mathrm{mg} \mathrm{L}^{-1}$. According to the results obtained and the literature reports, storage was discarded and ASM1 model was used further on.

$K_{\mathrm{S}}$ and $q_{\mathrm{O}_{2} \max }$ were estimated by ASM1 model fitting to the respirograms obtained during the reactor operation. Table 5 presents average results obtained from 51 pulses made over 270 days of experiment. $K_{\mathrm{S}}$ values estimated from model fitting were within the range generally observed in wastewater treatment plants [48], and they were also similar to the $K_{\mathrm{S}}$ estimated by respirometry by Carucci et al. [49] in real filtered wastewater $\left(K_{\mathrm{S}}=12.3 \pm 0.3 \mathrm{mgCOD}-\mathrm{SL}^{-1}\right)$. The response time of the process was approximately $0.06 \mathrm{~h}$ ( $3.4 \mathrm{~min})$, similar to those previously reported by Vanrolleghem et al. [36]. The One-way ANOVA test revealed that $K_{\mathrm{S}}$ was not significantly affected by $D\left(F_{(4,46)}=0.253\right.$, $p=0.91)$. Regarding $q_{\mathrm{O}_{2} \max }$, there was a significant difference between different $D\left(F_{(4,46)}=4.617, p<0.05\right)$. Tukey's HSD post hoc test showed that this difference was between the extremes, i.e., between $q_{\mathrm{O}_{2} \text { max }}$ at $D=0.2$ and $2.0 \mathrm{~d}^{-1}$ (Table 5).

$K_{\mathrm{S}}$ and $q_{\mathrm{O}_{2} \max }$ were also estimated by respirometry from the injection of pulses of increasing concentration. Pulses of 10.5 , 21.0 , and $42.3 \mathrm{mg}$ COD-S L ${ }^{-1}$ were injected and between pulses the feeding was restored until stable DO readings were obtained to

Table 5

Average $K_{\mathrm{S}}$ and $q_{\mathrm{O}_{2}}$ max obtained by ASM1 model fitting of 51 pulses injected at five dilution rates $(D)$

\begin{tabular}{lrll}
\hline$D\left(\mathrm{~d}^{-1}\right)$ & Number of pulses & $K_{\mathrm{S}}\left(\mathrm{mgCOD}-\mathrm{SL}^{-1}\right)$ & $q_{\mathrm{O}_{2} \max }\left(\mathrm{h}^{-1}\right)$ \\
\hline 0.2 & 12 & $19.6 \pm 2.7$ & $0.11 \pm 0.02$ \\
0.3 & 9 & $18.7 \pm 2.5$ & $0.09 \pm 0.01$ \\
0.5 & 18 & $17.0 \pm 2.6$ & $0.07 \pm 0.01$ \\
0.9 & 6 & $15.8 \pm 2.1$ & $0.04 \pm 0.00$ \\
2.0 & 6 & $18.4 \pm 2.7$ & $0.08 \pm 0.01$ \\
Average & & $17.9 \pm 1.1$ & $0.08 \pm 0.01$ \\
\hline
\end{tabular}
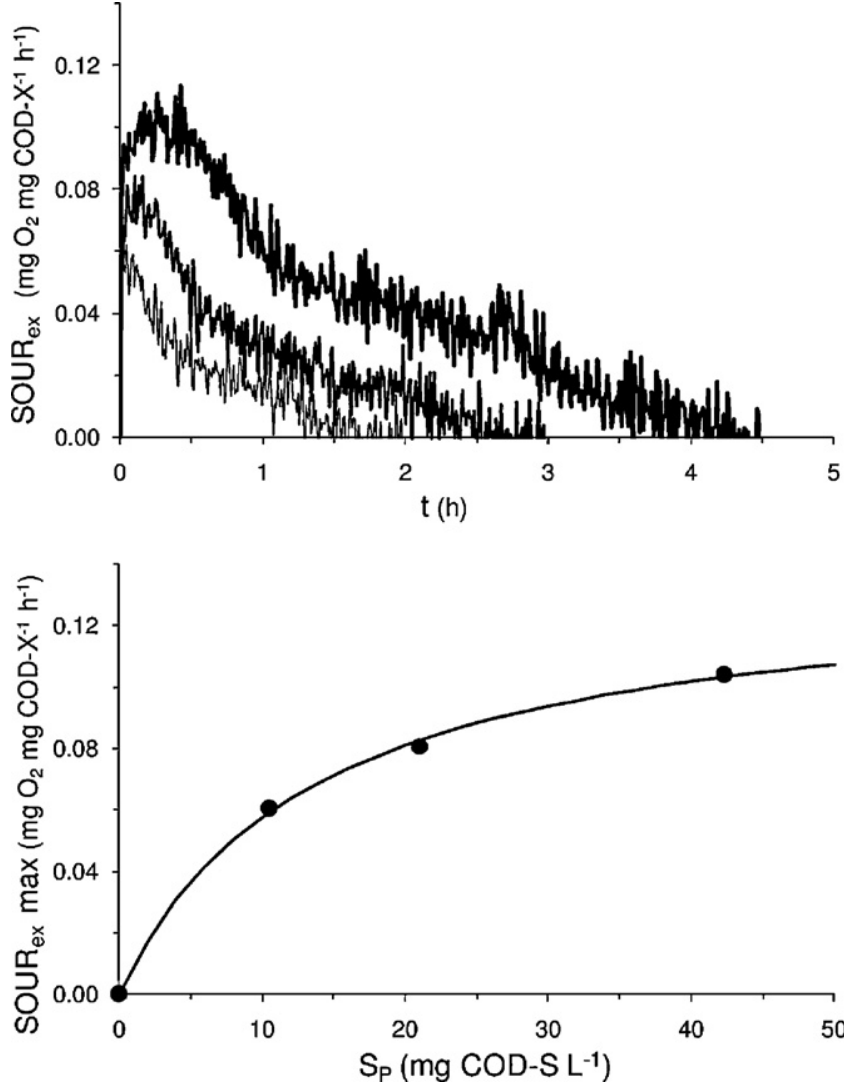

Fig. 6. Respirograms observed at three pulse concentrations $\left(\mathrm{mg} \mathrm{L}^{-1}\right)$ : 10.5 (darker line), 21.0 (medium line), and 42.3 (lighter line) (a); and relation between the maximum specific exogenous OUR $\left(q_{\mathrm{O}_{2}} \max \right)$ and pulse concentration $\left(S_{\mathrm{P}}\right)$ with corresponding Monod adjustment (solid line, $r^{2}=1.00$ ) (b).

ensure repeatability of the experimental conditions. Fig. 6a shows

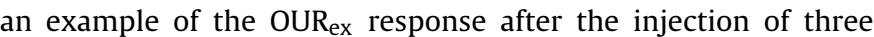
increasing concentration pulses. In each case, $\mathrm{OUR}_{\mathrm{ex}}$ max depended on $S_{\mathrm{p}}$. Fig. 6b shows that SOUR ex $_{\text {max }}$ followed a Monod-type kinetic in relation to the substrate concentration $\left(r^{2}=1.00\right)$. This allowed determining $K_{\mathrm{S}}$ and $q_{\mathrm{O}_{2} \max }$ (Eq. (8)), $15.5 \pm 2.4 \mathrm{mg}$ COD$\mathrm{SL}^{-1}$ and $0.12 \pm 0.01 \mathrm{~h}^{-1}$, respectively. By fitting ASM1 model simultaneously to the four respirograms used in the method of pulses of increasing substrate concentration (pulses of 10.5, 21.0 and $42.3 \mathrm{mgCOD}-\mathrm{S} \mathrm{L}^{-1}$ ), the values obtained for $K_{\mathrm{S}}$ and $q_{\mathrm{O}_{2} \max }$ were $19.9 \pm 0.06 \mathrm{mg} \mathrm{L}^{-1}$ and $0.10 \pm 0.02 \mathrm{~h}^{-1}$, respectively, with a correlation factor of 0.92 . By individual model fitting to the respirograms, model fitting to the $10.5 \mathrm{mgCOD}^{-S_{\mathrm{L}}-1}$ pulse failed; with the $21.0 \mathrm{mg}$ COD-S L ${ }^{-1}$ pulse, the $K_{\mathrm{S}}$ and $q_{\mathrm{O}_{2} \max }$ values estimated were $22.3 \pm 0.13 \mathrm{mgCOD}-\mathrm{S} \mathrm{L}^{-1}$ and $0.12 \pm 0.03 \mathrm{~h}^{-1}$, respectively $\left(r^{2}=0.96\right)$; and with the $42.3 \mathrm{mg} \mathrm{COD}-\mathrm{S} \mathrm{L}^{-1}$ pulse the values $33.7 \pm 0.8 \mathrm{mg} \mathrm{COD}-\mathrm{S} \mathrm{L}^{-1}$ and $0.12 \pm 0.02 \mathrm{~h}^{-1}$ were obtained for $K_{\mathrm{S}}$ and $q_{\mathrm{O}_{2} \text { max }}$, respectively $\left(r^{2}=0.93\right)$. The discrepancy of values obtained by model fitting a single pulse confirms previous observations which state that a number of pulses higher than one further improve parameters practical identifiability $[13,50]$. However, this compromises an increment in the computational effort, which has to be taken into account. The obtained values with the two respirometric data treatment methods were similar. Though the $K_{\mathrm{S}}$ associated error for model fitting was lower, the correlation factor of the model was worse than the one corresponding to the increasing substrate concentration pulses method.

For further comparison between both respirometric data treatment methods, results obtained by model fitting after the injection of a pulse of $21.8 \mathrm{mg} \mathrm{COD}-\mathrm{S} \mathrm{L}^{-1}$ were compared to those obtained 

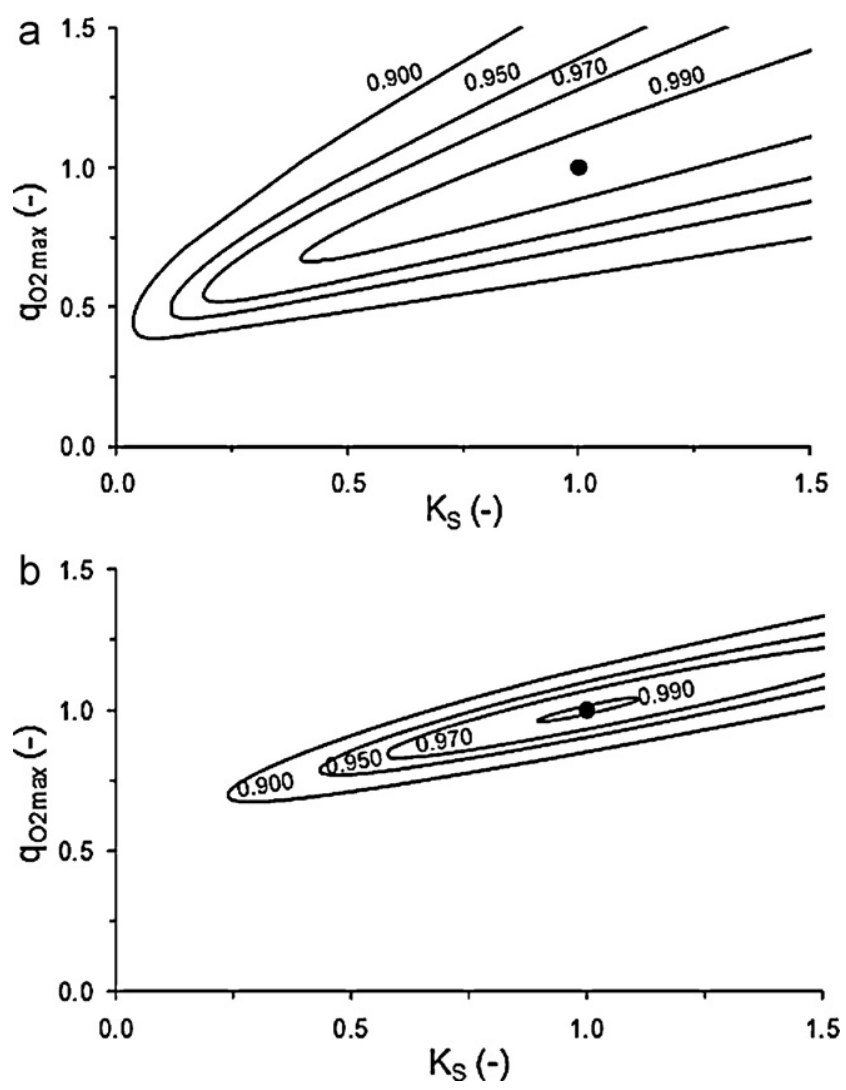

Fig. 7. Contour-plot of the correlation factor as a function of the substrate affinity constant $\left(K_{\mathrm{S}}\right)$ and the maximum specific exogenous OUR $\left(q_{\mathrm{O}_{2} \max }\right)$, for the model fitting method (a), and for the increasing substrate concentration pulses method (b).

after the injection of pulses of increasing concentration. The results of these sensitivity analyses are presented in Fig. 7, where the lines represent the dimensionless $K_{\mathrm{S}}$ and $q_{\mathrm{O}_{2}}$ max pairs for a specified $r^{2}$, as it is indicated. It is shown that the $r^{2}$ of the model fitting method is less sensitive to changes in $K_{\mathrm{S}}$ and $q_{\mathrm{O}_{2} \text { max }}$ than the $r^{2}$ of the method based on pulses of increasing concentration. This indicates that the method based on the injection of pulses of increasing concentration is more precise than simple single pulse model fitting and it is confirmed as a suitable method to estimate $q_{\mathrm{O}_{2} \text { max }}$ and $K_{\mathrm{S}}$. In order to improve the identifiability of parameters through ASM model fitting, more than one pulse is recommended. In the increasing substrate concentration pulses method three pulses are needed, which means the experimental effort of both methods is equivalent. Nevertheless, the ASM model fitting requires a much higher computational effort in order to treat a large amount of data, while the increasing substrate concentration pulses method uses a basic Monod-type model fitting.

$K_{\mathrm{S}}$ and $q_{\mathrm{O}_{2} \text { max }}$ were also determined from COD mass balance according to the chemostat method [3]. Fig. 8 shows the average specific substrate uptake rate expressed in oxygen demand versus the average substrate concentration at each dilution rate. The low $r^{2}$ obtained (0.61) did not allow the estimation of $K_{\mathrm{S}}$ nor $q_{\mathrm{O}_{2} \text { max }}$. The low sensitivity of substrate measurement methods and the difficulties of sampling heterogeneous biomass suspension are critical issues limiting the applicability of the chemostat method. Furthermore, the chemostat method applied in mixed cultures may be questioned in the sense that it involves changing the HRT, which is a selection pressure for microorganisms in continuous culture. Consequently, the selection of slower- or faster-growing microorganisms occurs [42]. The poor results obtained are in accordance with these drawbacks. Additionally, the time consuming nature of

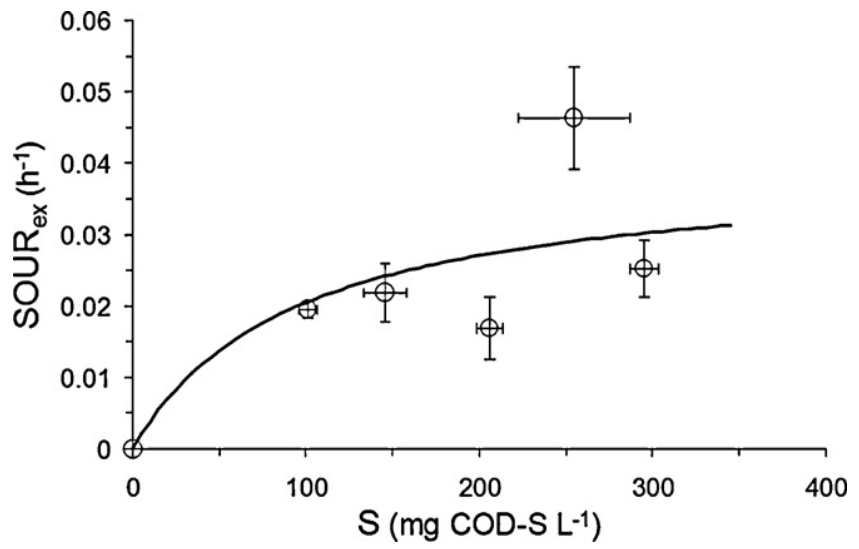

Fig. 8. Average specific exogenous OUR (SOUR $\mathrm{ex}_{\mathrm{e}}$ ) versus average $S$ for each dilution rate $(\bigcirc)$, and best fitting Monod model (solid line, $r^{2}=0.61$ ).

this method allows to conclude that no one single advantage can be pointed out to the chemostat method, in comparison with the simple in situ pulse respirometric techniques whatever the method used for mixed cultures parameters retrieval, although different methods of calculation have different precision and sensitivity. Therefore, the estimation of kinetic and stoichiometric parameters in mixed aerobic cultures should be always performed by using in situ respirometric techniques.

\section{Conclusions}

In situ pulse respirometry was applied to estimate stoichiometric and kinetic parameters in activated sludge systems, and a comparison with the chemostat method based on COD mass balances was done. $Y_{\mathrm{X} / \mathrm{S}}, m, b_{\mathrm{H}}, q_{\mathrm{O}_{2} \text { max }}$ and $K_{\mathrm{S}}$ were better estimated by respirometry than by chemostat mass balance. A further comparison of two different respirometric methods, namely the injection of pulses of increasing concentration and model fitting to respirograms gave similar results. It is concluded that respirometry is a more satisfactory method than mass balance and that within respirometric methods, the injection of pulses of increasing concentration presents several advantages compared to model fitting to respirograms, mainly simpler experimental data interpretation and better results confidence.

\section{Acknowledgements}

This project was financed by the European Union in the Framework of the Marie Curie Actions (IRG4 6647). C.S. Oliveira and F. Thalasso received a grant from Fundação para a Ciência e a Tecnologia (SFRH/BD/32289/2006 and SFRH/BI/15847, respectively). A. Ordaz received a grant from Conacyt (\#208321).

\section{References}

[1] H. Spanjers, I. Takacs, H. Brouwer, Direct parameter extraction from respirograms for wastewater and biomass characterization, Water Sci. Technol. 39 (4) (1999) 137-145.

[2] P.A. Vanrolleghem, W. Verstraete, Simultaneous biokinetic characterization of heterotrophic and nitrifying populations of activated-sludge with an online respirographic biosensor, Water Sci. Technol. 28 (11-12) (1993) 377-387.

[3] L.C. Duarte, A.P. Nobre, F.M. Gírio, M.T. Amaral-Collaço, Determination of the kinetic parameters in continuous cultivation by Debaryomyces hansenii grown on D-xylose, Biotechnol. Tech. 8 (12) (1994) 859-864.

[4] N. Lovanh, C.S. Hunt, P.J.J. Alvarez, Effect of ethanol on BTEX biodegradation kinetics: aerobic continuous culture experiments, Water Res. 36 (15) (2002) 3739-3746.

[5] S.E. Agarry, T.O.K. Audu, B.O. Solomon, Substrate inhibition kinetics of phenol degradation by Pseudomonas fluorescence from steady state and wash-out data, Int. J. Environ. Sci. Technol. 6 (3) (2009) 443-450. 
[6] K. Kovarova-Kovar, T. Egli, Growth kinetics of suspended microbial cells: from single-substrate-controlled growth to mixed-substrate kinetics, Microbiol. Mol. Biol. Rev. 62 (3) (1998) 646-666

[7] A.L. Koch, Microbial physiology and ecology of slow growth, Microbiol. Mol. Biol. Rev. 61 (3) (1997) 305-318.

[8] C.S. Oliveira, A. Ordaz, J. Alba, M. Alves, E.C. Ferreira, F. Thalasso, Determination of kinetic and stoichiometric parameters of Pseudomonas putida F1 by chemostat and in situ pulse respirometry, Chem. Prod. Process Modell. 4 (2) (2009) $1-14$.

[9] A. Ordaz, C.S. Oliveira, J. Alba, M. Carrión, F. Thalasso, Determination of apparent kinetic and stoichiometric parameters in a nitrifying fixed-bed reactor by in situ pulse respirometry, Biochem. Eng. J. 55 (2) (2011) 123-130.

[10] J.S. Cech, J. Chudoba, P. Grau, Determination of kinetic constants of activatedsludge microorganisms, Water Sci. Technol. 17 (2-3) (1985) 259-272.

[11] H. Spanjers, P. Vanrolleghem, Respirometry as a tool for rapid characterization of waste-water and activated-sludge, Water Sci. Technol. 31 (2) (1995) 105-114.

[12] R. Riefler, D. Ahlfeld, B. Smets, Respirometric assay for biofilm kinetics estimation: parameter identifiability and retrievability, Biotechnol. Bioeng. 57 (1) (1998) 35-45.

[13] J. Seoane, G. Sin, L. Lardon, K.V. Gernaey, B.F. Smets, A new extant respirometric assay to estimate intrinsic growth parameters applied to study plasmid metabolic burden, Biotechnol. Bioeng. 105 (1) (2010) 141-149.

[14] C.T. Goudar, T.G. Ellis, Explicit oxygen concentration expression for estimating extant biodegradation kinetics from respirometric experiments, Biotechnol. Bioeng. 75 (1) (2001) 74-81.

[15] D. Dochain, P.A. Vanrolleghem, M. Vandaele, Structural identifiability of biokinetic models of activated-sludge respiration, Water Res. 29 (11) (1995) 2571-2578.

[16] U. Sollfrank, W. Gujer, Characterization of domestic wastewater for mathematical modelling of the activated sludge process, Water Sci. Technol. 23 (4-6) (1991) 1057-1066.

[17] G. Insel, O. Karahan, S. Ozdemir, L. Pala, T. Katipoglu, E.U. Cokgor, D. Orhon, Unified basis for the respirometric evaluation of inhibition for activated sludge J. Environ. Sci. Health A: Toxic/Hazard. Subst. Environ. Eng. 41 (9) (2006) 1763-1780.

[18] Z. Kong, P. Vanrolleghem, P. Willems, W. Verstraete, Simultaneous determination of inhibition kinetics of carbon oxidation and nitrification with respirometer, Water Res. 30 (4) (1996) 825-836.

[19] A. Guisasola, I. Jubany, J. Baeza, J. Carrera, J. Lafuente, Respirometric estimation of the oxygen affinity constants for biological ammonium and nitrite oxidation, J. Chem. Technol. Biotechnol. 80 (2005) 388-396.

[20] F. Lagarde, M.H. Tusseau-Vuillemin, P. Lessard, A. Héduit, F. Dutrop, J.M. Mouchel, Variability estimation of urban wastewater biodegradable fractions by respirometry, Water Res. 39 (19) (2005) 4768-4778

[21] M. Spérandio, V. Urbain, P. Ginestet, M.J. Audic, E. Paul, Application of COD fractionation by a new combined technique: comparison of various wastewaters and sources of variability, Water Sci. Technol. 43 (1) (2001) 181-190.

[22] P. Van Bodegom, Microbial maintenance: a critical review on its quantification, Microb. Ecol. 53 (4) (2007) 513-523.

[23] J.B. Russell, G.M. Cook, Energetics of bacterial-growth - balance of anabolic and catabolic reactions, Microbiol. Rev. 59 (1) (1995) 48-62.

[24] E. Contreras, N. Bertola, N. Zaritzky, The application of different techniques to determine activated sludge kinetic parameters in a food industry wastewater, Water SA 27 (2) (2001) 169-176.

[25] APHA, Standard Methods for the Examination of Water and Wastewater, 20th ed., American Publishers Health Association, Washington, DC, 1999.

[26] A. Badino, M. Facciotti, W. Schmidel, Improving $k_{\mathrm{L}} a$ determination in fungal fermentation, taking into account electrode response time, J. Chem. Technol. Biotechnol. 75 (2000) 469-474.

[27] K. Dircks, P. Pind, H. Mosbaek, M. Henze, Yield determination by respirometry the possible influence of storage under aerobic conditions in activated sludge, Water SA 25 (1) (1999) 69-74.

[28] A. Ordaz, C.S. Oliveira, R. Aguilar, M. Carrión, E.C. Ferreira, M. Alves, F. Thalasso, Kinetic and stoichiometric parameters estimation in a nitrifying bubble column through "in-situ" pulse respirometry, Biotechnol. Bioeng. 100 (1) (2007) 94-102.
[29] T.G. Ellis, B.F. Smets, B.S. Magbanua, C.P.L. Grady, Changes in measured biodegradation kinetics during the long-term operation of completely mixed activated sludge (CMAS) bioreactors, Water Sci. Technol. 34 (5-6) (1996) $35-42$.

[30] B.F. Smets, T.G. Ellis, S. Brau, R.W. Sanders, C.P.L. Grady, Quantification of the kinetic differences between communities isolated from completely mixed activated-sludge systems operated with or without a selector using a novel respirometric method, Water Sci. Technol. 30 (11) (1994) 255-261

[31] S.J. Pirt, The maintenance energy of bacteria in growing cultures, Proc. R. Soc. Lond. B 163 (1965) 224-231.

[32] O.M. Neijssel, D.W. Tempest, Bioenergetic aspects of aerobic growth of Klebsiella aerogenes NCTC 418 in carbon-limited and carbon-sufficient culture, Arch. Microbiol. 107 (1976) 215-221.

[33] S.J. Pirt, Maintenance energy: a general model for energy-limited and energysufficient growth, Arch. Microbiol. 133 (1982) 300-302.

[34] G. Sin, A. Guisasola, D.J.W.D. Pauw, J.A. Baeza, J. Carrera, P.A. Vanrolleghem, A new approach for modelling simultaneous storage and growth processes for activated sludge systems under aerobic conditions, Biotechnol. Bioeng. 92 (5) (2005) 600-613.

[35] Z. Kong, P. Vanrolleghem, W. Verstraete, Automated respiration inhibition kinetics analysis ARIKA with a respirographic biosensor, Water Sci. Technol. 30 (4) (1994) 275-284.

[36] P. Vanrolleghem, G. Sin, V. Gernaey, Transient response of aerobic and anoxic activated sludge activities to sudden substrate concentration changes, Biotechnol. Bioeng. 86 (4) (2004) 277-290.

[37] M. Henze, C.P.L Grady Jr, W. Gujer, Gv.R. Marais, T. Matsuo, Activated sludge model no. 1, IAWQ Scientific and Technical Report No. 1, London, 1987.

[38] W. Gujer, M. Henze, T. Mino, M. van Loosdrecht, Activated sludge model no. 3, Water Sci. Technol. 39 (1) (1999) 183-193.

[39] K. Orupold, A. Masirin, T. Tenno, Estimation of biodegradation parameters of phenolic compounds on activated sludge by respirometry, Chemosphere 44 (5) (2001) 1273-1280.

[40] T.W. Kirkman, Statistics to Use, 1996. http://www.physics.csbsju.edu/stats/.

[41] D. Di Trapani, M. Capodici, A. Cosenza, G. Di Bella, G. Mannina, M. Torregrossa, G. Viviani, Evaluation of biomass activity and wastewater characterization in a UCT-MBR pilot plant by means of respirometric techniques, Desalination 269 (1-3) (2011) 190-197.

[42] L. Novak, L. Larrea, J. Wanner, Estimation of maximum specific growthrate of heterotrophic and autotrophic biomass - a combined technique of mathematical-modeling and batch cultivations, Water Sci. Technol. 30 (11) (1994) 171-180

[43] M.C.M. van Loosdrecht, M. Henze, Maintenance, endogeneous respiration, lysis, decay and predation, Water Sci. Technol. 39 (1) (1999) 107-117.

[44] C. Krishna, M.C.M. van Loosdrecht, Effect of temperature on storage polymers and settleability of activated sludge, Water Res. 33 (10) (1999) 2374-2382.

[45] A.S. Ciggin, O. Karahan, D. Orhon, Effect of feeding pattern on biochemica storage by activated sludge under anoxic conditions, Water Res. 41 (4) (2007) 924-934.

[46] P.A. Vanrolleghem, K. Gernaey, F. Coen, B. Petersen, B. De Clercq, J.P. Ottoy, Limitations of short-term experiments designed for identification of activated sludge biodegradation models by fast dynamic phenomena, in: Proceedings of the 7th IFAC Conference on Computer Applications in Biotechnology CAB7, Osaka, Japan, May 31-June 4, 1998.

[47] L. Prendl, H. Kroiss, Bulking sludge prevention by an aerobic selector, Water Sci. Technol. 38 (8-9) (1998) 19-27.

[48] Metcalf and Eddy Inc., Wastewater Engineering: Treatment and Reuse, Fourth Edition. Civil and Environmental Engineering Series, McGraw-Hill International Editions, 2003.

[49] A. Carucci, D. Dionisi, M. Majone, P. Smurra, Aerobic storage by activated sludge on real wastewater, Water Res. 35 (16) (2001) 3833-3844.

[50] P.A. Vanrolleghem, M. Vandaele, D. Dochain, Practical identifiability of a biokinetic model of activated-sludge respiration, Water Res. 29 (11) (1995) 2561-2570. 